\title{
Curing of bisphenol A-aniline based benzoxazine using phenolic, amino and mercapto accelerators
}

\author{
A. Ručigaj, B. Alič, M. Krajnc, U. Šebenik* \\ University of Ljubljana, Faculty of Chemistry and Chemical Technology, Večna pot 113, 1000 Ljubljana, Slovenia
}

Received 15 December 2014; accepted in revised form 8 February 2015

\begin{abstract}
The curing of bisphenol A-aniline based benzoxazine was studied applying different accelerators $\left(4,4^{\prime}\right.$-thiodiphenol, o-dianisidine, 2-mercaptobenzimidazole and 4-mercaptophenol) to initiate the catalytic ring-opening of benzoxazine. Possible pathways of benzoxazine ring-opening, polymerization and cross-linking without and with the addition of different accelerators are presented. The curing kinetics was investigated by model-free kinetic analysis of experimental data obtained by differential scanning calorimetry (DSC). The addition of different accelerators significantly reduced the onset temperature of curing in dynamic experiments. The effects of accelerators on the results of isothermal conversion prediction were studied and discussed in detail. Among the used accelerators, thiodiphenol showed the best accelerating efficiency and was consequently used in further studies, where its amount was varied. By low heating rate DSC analysis the catalytic ring-opening, thermally accelerated ring-opening and the diffusion-controlled steps were identified. The amount of added accelerator affected particularly the ring-opening and diffusion-controlled steps.
\end{abstract}

Keywords: thermosetting resins, benzoxazine, accelerators, curing mechanisms, deconvolution

\section{Introduction}

Recently, much attention has been given to the development of benzoxazine-based family of phenolic resins due to their adaptable mechanical and physical properties, which are often considerably better than those of traditional phenolic resins [1]. Benzoxazines are a class of heterocyclic compounds with typically one or two oxazine rings in their molecules. They are synthesized from a phenolic derivative, a primary amine and formaldehyde. Polybenzoxazines are formed by ring-opening polymerization of benzoxazine molecules. Properties of polybenzoxazines can be easily adjusted due to a high design flexibility of their molecular architecture, which opens great opportunities in further enhancement of benzoxazine resins properties. They have demonstrated various attractive properties such as good thermal, mechanical, chemical, electrical and physical prop- erties, high char yields, high glass transition temperature $\left(T_{\mathrm{g}}\right)$, low water absorption, near-zero shrinkage, and low flammability. The important factor, which has great influence on their adoption, both in the academic and industrial communities, is also their relative cheapness. However, the disadvantages associated with polybenzoxazines, which need to be addressed, are their high curing temperature (i.e. polymerization and cross-linking temperature), brittleness and outgassing during the curing process [2-10].

The classical method for production of polybenzoxazines is polymerization of benzoxazine monomers at high temperature (usually at $T>180^{\circ} \mathrm{C}$ ) without the addition of an accelerator [1], which may be a catalyst, initiator, or co-monomer. However, the high temperature, which is required for the curing process, may in some cases lead to thermal degradation of

\footnotetext{
$\overline{{ }^{*} \text { Corresponding author, e-mail: urska.sebenik@fkkt.uni-lj.si }}$

(C) BME-PT
} 
the corresponding resin [11]. Lower curing temperature would therefore lead to a significant process and resulting material improvement. In order to respond to this issue, a considerable amount of different catalysts have been applied to promote ringopening polymerization, including nucleophilic catalysts and Lewis acids [12-14]. Also the use of carboxylic acid groups as accelerators have been extensively studied and a significant decrease in the polymerization temperature has been observed [15-17]. Even though, the studied catalysts showed good catalytic activities, there is still much effort needed for further lowering of the polymerization temperature [18]. The important question, when using benzoxazines of different chemical structures in combination with different catalysts, is the effect of functional groups present in benzoxazine and catalyst molecules not only on the ring-opening but also on the polymerization and cross-linking reactions. Therefore, it is of great importance to understand the nature of the cured material and the effect certain functional group has on the curing process, i.e. on the ring-opening, polymerization and cross-linking mechanisms [1, 2, 12, 14, 19-29].

The terminology used for accelerators is varied and may sometimes cause confusion since the terms accelerator, catalyst, promoter, initiator, etc., are sometimes used loosely even though they can apply to very specific types of materials having distinctly different characteristics and functions. This study focuses on benzoxazine resin systems and the term accelerator is used to describe a variety of compounds used to increase the reaction rate, whatever the reaction mechanism. The term accelerator is applied instead of terms catalyst, initiator, and/or co-monomer, since the applied accelerators initiate ring-opening polymerization and co-react with benzoxazine to form polybenzoxazine. In the literature of curing reactions the term catalyst is often used, but by definition a catalyst lowers the activation energy of a chemical process without being a reactant.

In the present study, we have examined the accelerating efficiency of a number of different accelerators in the curing process of bisphenol A-aniline based benzoxazine (BOX). Possible pathways of benzoxazine ring-opening, polymerization and cross-linking without and with the addition of different accelerators are presented. The curing kinetics was investigated by model-free kinetic analysis of exper- imental data obtained by differential scanning calorimetry (DSC). The basic assumption for the application of DSC technique for curing process following is that the rate of kinetics process is proportional to the measured heat flow [30-32]. Among tested accelerators, thiodiphenol showed the best effect on the curing process of benzoxazine in terms of conversion predictions obtained by isoconversional model-free approach. For that reason the effects of different amounts of thiodiphenol on the curing process of benzoxazine were studied in detail.

\section{Experimental}

\subsection{Materials}

For the kinetic studies, benzoxazine based on bisphenol A and aniline (BOX, 98\%) was employed along with different polymerization accelerators. As accelerators 4,4'-thiodiphenol (TDP, 99\%), $o$-dianisidine (DA, 97\%), 2-mercaptobenzimidazole (MBI, 98\%) and 4-mercaptophenol (MP, 90\%) were used as received from Sigma-Aldrich Chemie $\mathrm{GmbH}$, (Steinheim, Germany). Bisphenol A-aniline based benzoxazine (commercial name Araldite MT 35600) was kindly provided by Huntsman Advanced Materials (BVBA, Everberg, Belgium).

\subsection{Sample preparation}

Homogeneous mixtures of benzoxazine monomer and accelerators were prepared by dissolving them in $10 \mathrm{~mL}$ of dichloromethane by mixing with magnetic stirrer for 15 minutes. The solvent was then removed from samples by evaporation at room temperature for 12 hours and subsequent drying for 4 hours in vacuum oven at $60^{\circ} \mathrm{C}$. For DSC experiments benzoxazine mixtures with $20 \mathrm{~mol}$ of accelerator (TDP, DA, MBI and MP) per $100 \mathrm{~mol}$ of benzoxazine (16.7 mol\%) were prepared. The amounts of different accelerators in benzoxazine mixtures are given in $\mathrm{mol} \%$ in order to provide comparable quantity between the mixtures. When the amount of accelerator on benzoxazine/thiodiphenol mixture curing was investigated, the prepared benzoxazine/ thiodiphenol contained 1, 2, 5, 10, 20, 35 and $50 \mathrm{wt} \%$ to the weight of benzoxazine.

\subsection{Differential scanning calorimetry (DSC)}

The DSC measurements were performed on Mettler Toledo DSC 1 instrument with intra-cooler using STAR software. In and $\mathrm{Zn}$ standards were used for the temperature calibration and for the determina- 
tion of the instrument time constant. Samples of around $10 \mathrm{mg}$ were weighed in standard $40 \mu \mathrm{L}$ aluminum pans. DSC measurements were performed in nitrogen atmosphere with $30 \mathrm{~mL} / \mathrm{min}$ nitrogen flow rate. For investigation of the effect of accelerator type on curing kinetics the samples were subjected to four different heating rates $\left(5,10,15\right.$ and $\left.20^{\circ} \mathrm{C} / \mathrm{min}\right)$ in the temperature range from 20 to $350^{\circ} \mathrm{C}$. To study the effect of different amounts of thiodiphenol on the curing process also a lower heating rate of $1{ }^{\circ} \mathrm{C} /$ min was used.

\section{Results and discussion 3.1. Curing reaction}

Curing (polymerization and cross-linking) of benzoxazine is thermally accelerated cationic ringopening polymerization, which may be carried out with or without using accelerators (Figure 1). Different accelerators, which lower benzoxazine curing temperature, may bear different functional groups capable of initiating or catalyzing the oxazine ring opening. This is why several mechanisms were proposed for benzoxazine curing [13, 14, 26, 33-35]. Regardless to the type of the accelerator used, the mechanism of the curing process involves several steps, which complicate the kinetics. The curing is always autocatalyzed as the newly produced hydroxyl groups in phenolic structure (compound III in Figure 1a) act as an additional initiator. Moreover, in the early stage of curing, the reaction medium is a liquid composed of benzoxazine, accelerator and just formed oligomers. As the reaction progresses, the average molecular weight, the viscosity and the glass transition temperature $\left(T_{\mathrm{g}}\right)$ of the resin increase. Therefore the molecular mobility, in turn, decreases, which affects the curing kinetics. The latter becomes diffusion rather than kinetically controlled $[1,36]$.

Figure 2 shows DSC thermograms of benzoxazine and its mixtures with $16.7 \mathrm{~mol} \%$ of accelerators in the temperature range from 20 to $350^{\circ} \mathrm{C}$ using heating rate of $20^{\circ} \mathrm{C} / \mathrm{min}$. The addition of accelerator significantly reduced the onset temperature of curing process, which was detected as an exothermic signal. This exothermic peak for the accelerated benzoxazine was broader than that for the unaccelerated benzoxazine, implying presence of multiple reactions during the curing process with accelerators. The presumed reaction pathways occurring in the presence of accelerators are drawn in Figure 1b-1e.
Phenols, such as 4,4'-thiodiphenol and 4-mercaptophenol, can initiate oxazine ring opening and accelerate benzoxazine polymerization by the formation of an intermolecular hydrogen bond and subsequent reaction at the ortho position of the phenol or other benzoxazine molecule (Figure 1c). The other possible ring-opening mechanism is the initial protonation of benzoxazine, where protons behave as an actual catalyst. The protonation is followed by condensation reaction of the iminium species and the phenolate or other benzoxazine molecule to a phenolic structure (Figure 1b) [33]. The initiation by protonation or by intermolecular bond formation (hydrogen bond) can take place at either the nitrogen atom or the oxygen atom, but it was found, that in the case of protonation, the oxygen protonated species are reactive, whereas the nitrogen protonated species are stable [26] (Figure 1b).

On the other hand, imidazoles, such as 2-mercaptobenzimidazole, and aromatic amines, such as dianisidine, accelerate benzoxazine polymerization through the formation of an arylether structure (N,O-acetal-type linkage) [14, 34] (compound VI in Figure 1d). Formation of N,O acetal intermediate is present especially in the case of $\mathrm{N}$-aryl-1,3-benzoxazines, before it rearranges to Mannich-type structure at higher temperatures. The arylether structure is thermally unstable and undergoes structural transformation to the phenolic-type with Mannich bridge $\left(-\mathrm{CH}_{2}-\mathrm{NR}-\mathrm{CH}_{2}-\right)$ at elevated temperature $[1,2]$.

Curing of benzoxazine with accelerators bearing thiol group is proposed to proceed according to Colbert reaction mechanism (Figure 1e) [37]. Initially the thiol proton protonates the nitrogen in oxazine ring. Then the sulfide attacks the adjacent methylene group located between the nitrogen and the oxygen. The thioether bond is created, which causes benzoxazine ring opening and phenolic hydroxyl group formation. The newly formed phenolic hydroxyl group of compound VII in Figure 1e is available for further reactions with benzoxazine.

\subsection{Kinetic analysis}

Kinetic analysis of non-isothermal resin-cured system is based on the rate equation and can be performed by the multiple heating rates $[38,39]$. This method is attractive since the kinetic data can be obtained in short period of time. The rate of the curing process is considered to be a function of two variables, $T$ and $\alpha$ (Equation (1)): 


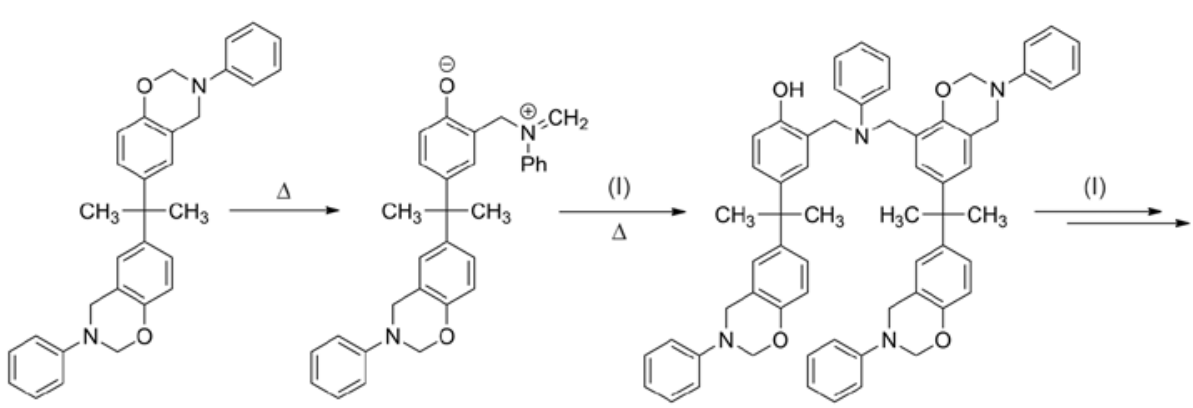

(I)
(II)

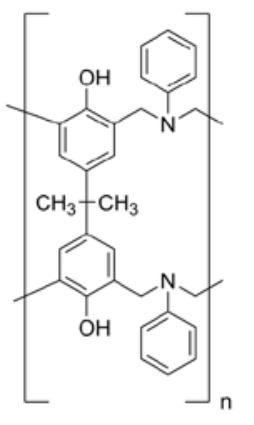

Mannich bridge structure

a)

b)

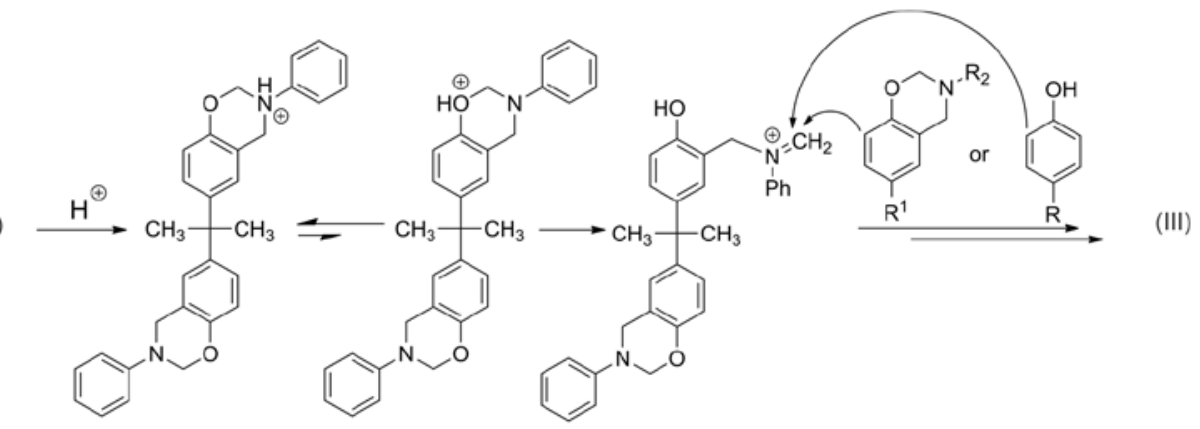

c)

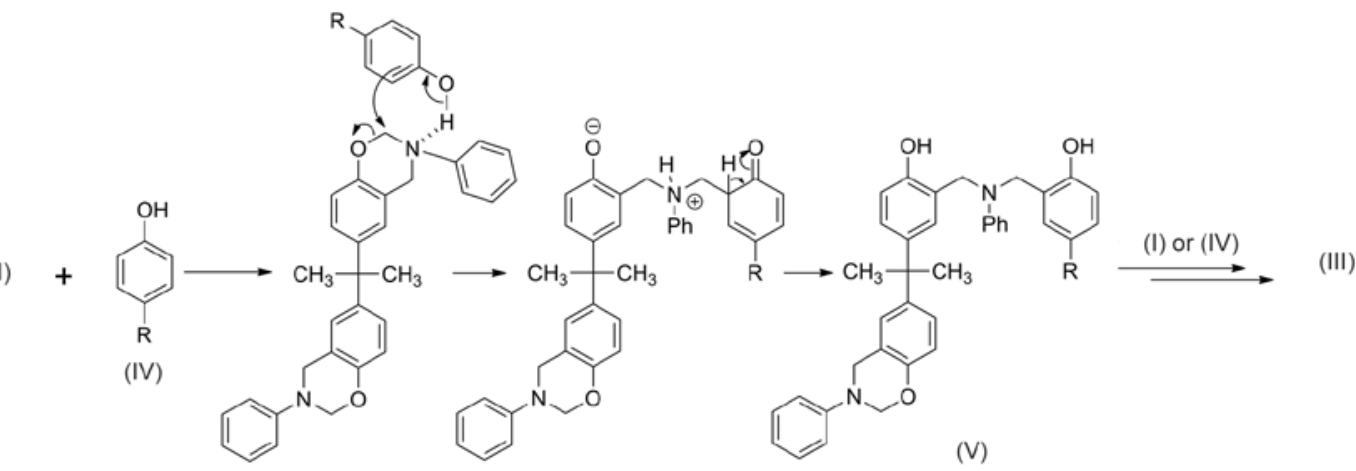

d)

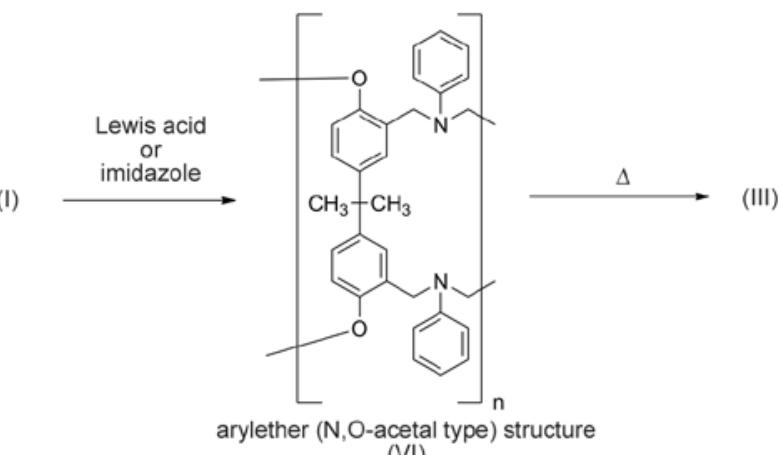

(VI)

e)

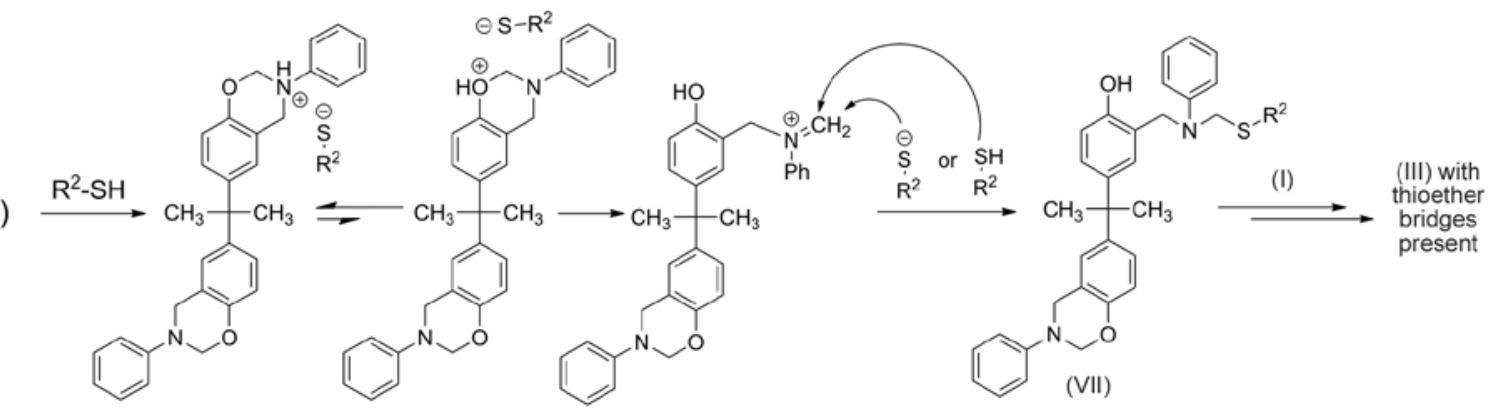

Figure 1. Possible pathways of benzoxazine polymerization and cross-linking, a) thermally accelerated ring-opening, b) ringopening by protonation, c) ring-opening by hydrogen bond formation, d) polymerization through formation of an arylether structure (N,O-acetal-type linkage), e) Colbert reaction mechanism via two-step acid catalyzed nucleophilic addition 


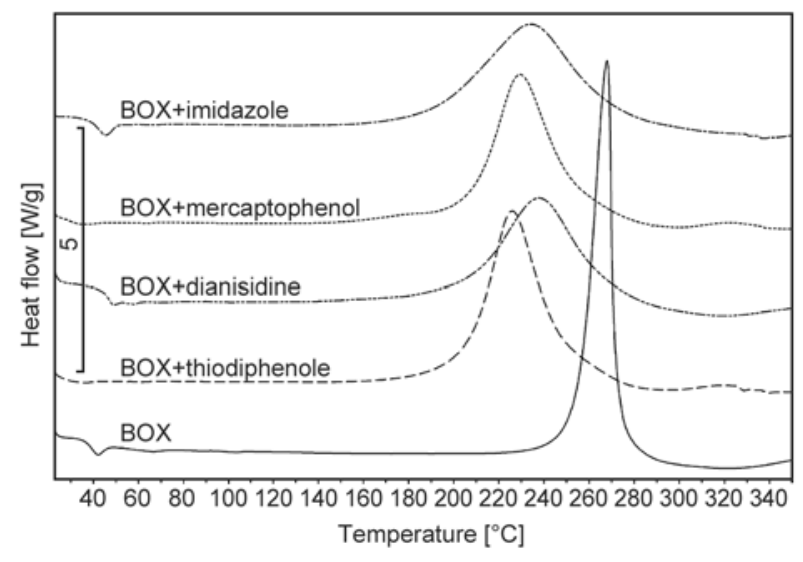

Figure 2. DSC thermograms of pure benzoxazine (BOX) and its mixtures with $16.7 \mathrm{~mol} \%$ of selected accelerators in the temperature range from 20 to $350^{\circ} \mathrm{C}$ at a heating rate of $20^{\circ} \mathrm{C} / \mathrm{min}$

$$
\frac{\mathrm{d} \alpha}{\mathrm{d} t} \equiv \beta \frac{\mathrm{d} \alpha}{\mathrm{d} T}=k(T) f(\alpha)
$$

where $k(T)$ is a temperature-dependent reaction rate constant, $f(\alpha)$ is the reaction model, $\beta$ is the heating rate in ${ }^{\circ} \mathrm{C} / \mathrm{min}$ and $\mathrm{d} \alpha / \mathrm{d} t$ is the conversion rate in $\mathrm{s}^{-1}$. Temperature dependence on rate constant is represented through the Arrhenius equation (Equation (2)):

$k(T)=A \exp \left(-\frac{E_{\mathrm{a}}}{R T}\right)$

where $A$ is the pre-exponential factor in $\mathrm{s}^{-1}, E_{\mathrm{a}}$ is the apparent activation energy in $\mathrm{J} / \mathrm{mol}, R$ is the ideal gas constant in $\mathrm{J} \cdot \mathrm{mol}^{-1} \cdot \mathrm{K}^{-1}$, and $T$ is the absolute temperature in K. Four kinetic methods widely used in order to study dynamic kinetics of thermosetting polymers are Kissinger (Equation (3)), Ozawa (Equation (4)), Friedman (Equation (5)), and Flynn-WallOzawa (Equation (6)) methods [40-43]:

$\ln \left(\frac{\beta}{T_{\mathrm{p}}^{2}}\right)=\ln \left(\frac{Q_{\mathrm{p}} A R}{E_{\mathrm{a}}}\right)-\frac{E_{\mathrm{a}}}{R T_{\mathrm{p}}}$

$\ln \beta=\ln \left(\frac{A E_{\alpha}}{R}\right)-\ln F(\alpha)-5.331-1.052\left(\frac{E_{\alpha}}{R T_{p}}\right)$

$$
\begin{aligned}
& \ln \frac{\mathrm{d} \alpha}{\mathrm{d} t}=\ln [A f(\alpha)]-\frac{E_{\mathrm{a}}}{R T} \\
& \ln \beta=\ln \left(\frac{A E_{\alpha}}{R}\right)-\ln g(\alpha)-5.331-1.052\left(\frac{E_{\alpha}}{R T}\right)
\end{aligned}
$$

where $F(\alpha)$ is a constant function, $g(\alpha)$ is the integral conversion function, $T_{\mathrm{p}}$ is the peak temperature and $Q_{\mathrm{p}}=[\mathrm{d} f(\alpha) / d \alpha]_{\alpha=\alpha \mathrm{p}}$.

The results of calculated apparent activation energies by using the Kissinger and Ozawa methods (Table 1) showed that TDP was a superior accelerator in the studied system, since the activation energy was the lowest among the used accelerators. However, it has to be mentioned that calculated activation energies were only apparent, which is why pure BOX has lower activation energy than BOX/DA and BOX/ MBI even though DA and MBI were labeled as accelerators. Such differences between the values with and without the accelerator can be expected, since the calculated value of $E_{\mathrm{a}}$ depends on how $T_{\mathrm{p}}$ value changes with heating rates for each of the studied systems. Therefore it is possible to obtain a higher $E_{\text {a }}$ value for a system with lower $T_{\mathrm{p}}$ values. The peak temperatures of BOX/DA and BOX/MBI were lower than that of BOX, which may indicate that curing started at lower temperatures and DA and MBI really accelerate the curing process. Slightly higher activation energies may be observed by using Ozawa method in comparison to Kissinger method, though. Further on, the curing kinetic study was extended to isothermal conversion prediction using the method by Vyazovkin in order to complement the picture of kinetic studies.

\subsection{Isothermal conversion prediction}

In thermoset industry practice, it is of great importance to be able to predict the conversion of a material during the curing process. To predict the curing kinetics of a complex reaction system, such as benzoxazine/accelerator reaction systems, the use model-

\begin{tabular}{|c|c|c|c|c|c|c|}
\hline \multirow[t]{2}{*}{ Accelerator } & \multicolumn{4}{|c|}{$\begin{array}{c}\mathbf{T}_{\mathbf{p}} \\
{\left[{ }^{\circ} \mathbf{C}\right]}\end{array}$} & \multicolumn{2}{|c|}{$\begin{array}{c}\mathbf{E}_{\mathbf{a}} \\
{[\mathrm{kJ} / \mathrm{mol}]}\end{array}$} \\
\hline & $5^{\circ} \mathrm{C} / \mathrm{min}$ & $10^{\circ} \mathrm{C} / \mathrm{min}$ & $15^{\circ} \mathrm{C} / \mathrm{min}$ & $20^{\circ} \mathrm{C} / \mathrm{min}$ & Kissinger & Ozawa \\
\hline BOX & 233 & 248 & 257 & 264 & 91,5 & 95,2 \\
\hline $\mathrm{BOX} / \mathrm{DA}$ & 218 & 227 & 232 & 238 & 137,9 & 139,0 \\
\hline BOX/MBI & 210 & 223 & 231 & 238 & 92,7 & 96,0 \\
\hline BOX/MP & 197 & 212 & 222 & 229 & 78,0 & 81,9 \\
\hline $\mathrm{BOX} / \mathrm{TDP}$ & 192 & 208 & 218 & 225 & 72,8 & 76,8 \\
\hline
\end{tabular}

Table 1. Apparent activation energies obtained from DSC experiments at various heating rates $(\beta)$ for the BOX and $\mathrm{BOX} /$ accelerator formulations using Kissinger and Ozawa method 
free isoconversional method developed by Vyazovkin [30-32] has been proposed. The isoconversional method enables simulation of the extent of reaction as a function of time in isothermal conditions using data obtained by dynamic experiments, without knowing the exact mechanism and individual reaction rate constants. Due to its proven great accuracy and wide applicability to any temperature program this approach has been widely used. In the applied isoconversional method the $E_{\alpha}$ value is determined as the value that minimizes the function (Equations (7) and (8)):

$\Phi\left(E_{\alpha}\right)=\sum_{\mathrm{i}=1}^{\mathrm{n}} \sum_{\mathrm{j} \neq 1}^{\mathrm{n}} \frac{J\left[E_{\alpha}, T_{\mathrm{i}}\left(t_{\alpha}\right)\right]}{J\left[E_{\alpha} T_{\mathrm{j}}\left(t_{\alpha}\right)\right]}=\min$

$J\left[E_{\alpha}, T_{\mathrm{i}}\left(t_{\alpha}\right)\right]=\int_{\mathrm{t}_{\alpha-\Delta \alpha}}^{\mathrm{t}_{\alpha}} \exp \left[\frac{-E_{\alpha}}{R T_{\mathrm{i}}(t)}\right] \mathrm{d} t$

where $i$ and $j$ denote different dynamic experiments, $T$ is temperature in $\mathrm{K}, R$ is the ideal gas constant in $\mathrm{J} /(\mathrm{mol} \cdot \mathrm{K}), E_{\alpha}$ is apparent activation energy for a specific conversion $\alpha$ in $\mathrm{J} / \mathrm{mol}, \Delta \alpha$ is the small increment in $\alpha$ (usually around 0.02 ), $t \alpha$ and $t_{\alpha+\Delta \alpha}$ are reaction times up to $\alpha$ or $\Delta \alpha$, respectively. In this study, the integral $J$ given in the Equation (2) was evaluated numerically from the experimental data by using trapezoidal rule. Repetition of minimization procedure in Equation (1) for each $\alpha$ resulted in the $E_{\alpha^{-}}$ dependence. After knowing the $E_{\alpha}$ vs. $\alpha$ relationship, the isoconversional method can be used to predict isothermal kinetic conversion as a function of reaction time for different temperature programs with the use of Equation (9):

$t_{\alpha}=\frac{\int_{0}^{t_{\alpha}} \exp \left(-\frac{E_{\alpha}}{R T\left(t_{\alpha}\right)}\right) \mathrm{d} t}{\exp \left(-\frac{E_{\alpha}}{R T_{0}}\right)}$

where $t_{\alpha}$ is the reaction time to a specific conversion $\alpha$ and $T_{0}$ is a fixed isothermal reaction temperature. $t_{\alpha}$ can be estimated by Equation (10) using results of dynamic experiment with a constant heating rate $(\beta)$ : $t_{\alpha}=\frac{\int_{0}^{\mathrm{T}_{\alpha}} \exp \left(-\frac{E_{\alpha}}{R T}\right) \mathrm{d} T}{\beta \exp \left(-\frac{E_{\alpha}}{R T_{0}}\right)}$

Figure 3 compares conversion predictions for benzoxazine/accelerator mixtures with that of benzoxazine without accelerator at $140,160,180$ and $200^{\circ} \mathrm{C}$.
As expected, at $140^{\circ} \mathrm{C}$ (Figure 3a) significantly higher conversions were predicted for curing with accelerators, which promote the ring-opening reaction. According to predictions (Figure 3a), the conversion without accelerator would be just little over $5 \%$ after 180 minutes at $140^{\circ} \mathrm{C}$. By increasing the temperature the predicted conversion after $180 \mathrm{~min}$ was significantly increased. The result is straightforward, since higher temperature increases ring-opening reaction rate and the rate of hydroxyl group formation. Newly formed hydroxyl groups further accelerate the curing of benzoxazine through initiation by protonation and/or intermolecular bond formation as depicted in Figures $1 \mathrm{~b}$ and $1 \mathrm{c}$, respectively. Due to the fact that the ring-opening reaction is exclusively thermally initiated in the absence of an accelerator, the most evident difference in the progress of the conversion with increasing temperature is noticeable in this case (Figure 3).

With increasing curing temperature also the predicted conversions increased for all benzoxazine/ accelerator mixtures as expected (Figure 3 ). The higher the temperature, the smaller the differences between benzoxazine/accelerator mixtures. Thiodiphenol (TDP) showed the best performance among the tested accelerators at $140^{\circ} \mathrm{C}$. Thus at higher temperatures both accelerators of phenol type showed similar efficiency. Interestingly, at higher curing times, the MP efficiency became even higher than that of TDP. Moreover, by a detailed inspection of conversion curves in Figures $3 a$ and $3 b$ it may be noticed that the MP efficiency was higher also at the very beginning of the curing process. The observations may be explained by the fact that MP contains two different functional groups, which accelerate benzoxazine curing, i.e. a phenol and a thiol group, while TDP contains only phenol groups. Thus, curing with TDP follows the mechanisms depicted in Figures $1 \mathrm{~b}$ and $1 \mathrm{c}$, while curing with MP follows the mechanism depicted Figure 1e as well. At lower curing times, the better MP accelerating efficiency may be attributed to the relatively fast reaction of thiol group with oxazine ring. Since-SH groups are consumed during the reaction their accelerating effect diminishes with time. At the same time, the newly formed -OH group (compound VII in Figure 1e) is sterically hindered, but still possesses an acceleration capability. As the concentration of phenol $-\mathrm{OH}$ groups was higher when TDP, instead of MP, was used, the curing with TDP (through mechanisms 

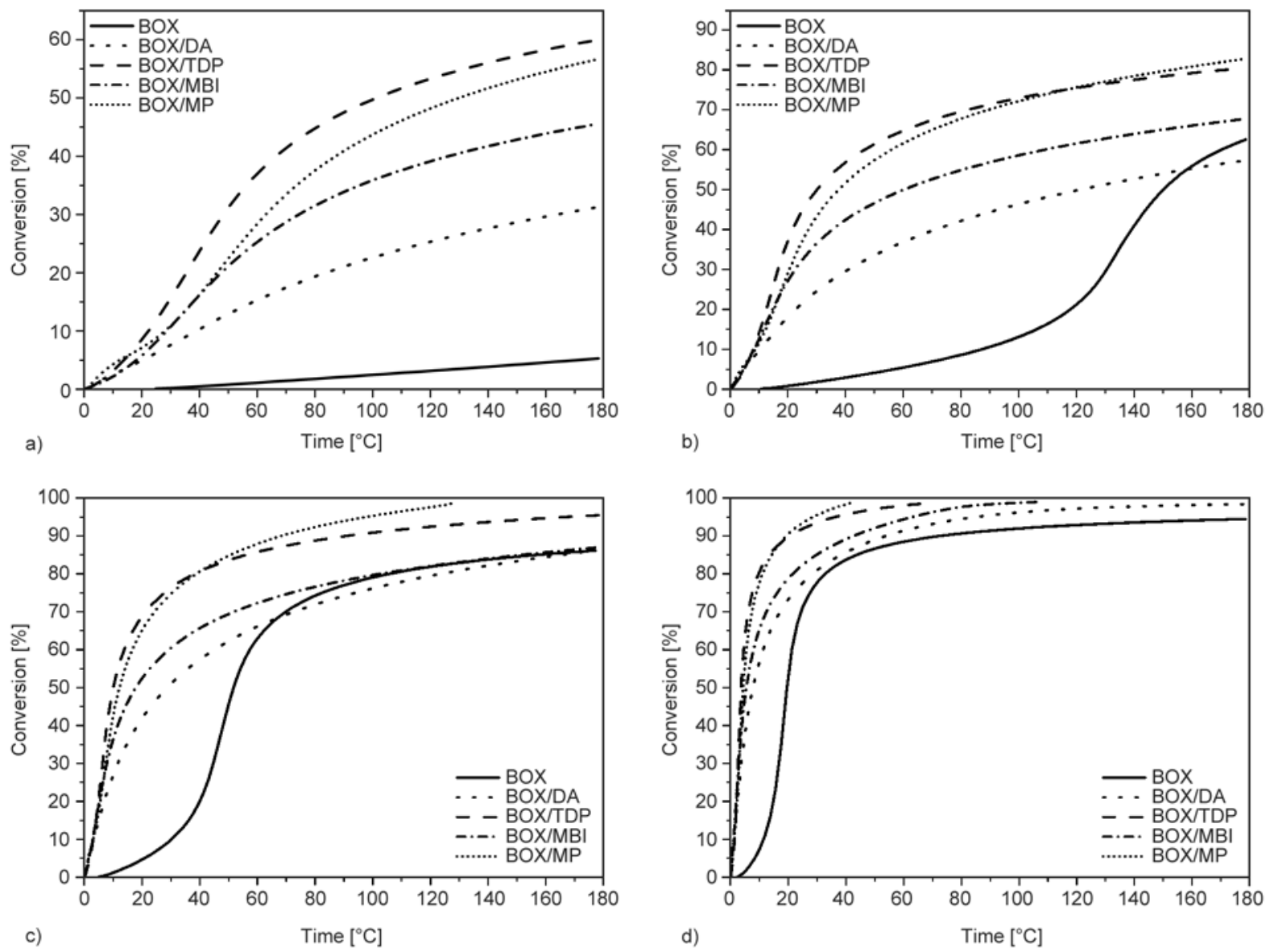

Figure 3. Conversion versus time at 140 (a), 160 (b), 180 (c) and $200^{\circ} \mathrm{C}$ (d) for benzoxazine (BOX) and its mixtures with different accelerators based on model-free isoconversional method

depicted in Figures $1 \mathrm{~b}$ and 1c) proceeded faster after -SH groups of MP were consumed. However, at higher curing times, the conversion of curing with MP became higher again, which may be attributed to the higher cross-linking density of molecules $\mathrm{V}$ formed in reaction with TDP (due to larger number of reactive ortho sites on phenol). As mentioned before, a higher cross-linking density leads to lower molecular mobility and the process becomes diffusion-controlled.

By comparing conversion evolutions of benzoxazine (BOX) with those of its mixtures, where curing through the formation of an arylether structure (DA and MBI) was accelerated, an interesting phenomenon may be observed, which may be explained by already discussed reaction mechanisms again. When the acceleration proceeds through the mechanism shown in Figure 1d, N,O-acetal type structure is formed, which is without any hydroxyl groups. Consequently, the concentration of hydroxyl groups may be higher if no DA or MBI are added. The higher the concentration of - $\mathrm{OH}$ groups, the higher the rate of autocatalyzed curing reaction. Thus, it is possible that the thermally initiated benzoxazine curing becomes faster than curing through the formation of an arylether structure. Of course, this is unlikely at lower temperatures and reaction times. To our opinion, this effect is observable in Figures $3 b$ and $3 \mathrm{c}$, where BOX curves overcome BOX/DA curves and reach BOX/MBI curves. However, for simulations at $200^{\circ} \mathrm{C}$, the conversion of BOX/DA and $\mathrm{BOX} / \mathrm{MBI}$ is once again higher than that of BOX, presumably due to the fast transformation of molecule VI to the Mannich bridge structure III. The $\mathrm{N}, \mathrm{O}$-acetal structure is thermally unstable and after the breakdown of the molecule VI, hydroxyl groups are formed, which leads to the final molecule III and higher simulated conversions of BOX/DA and BOX/MBI than BOX (Figure 3d).

\subsection{Curing behavior of benzoxazine using thiodiphenol as accelerator}

The model-free kinetics analysis showed that thiodiphenol is the best choice among the tested accelerators. Acceleration with thiodiphenol is efficient and gives polybenzoxazine with enhanced cross-linked 


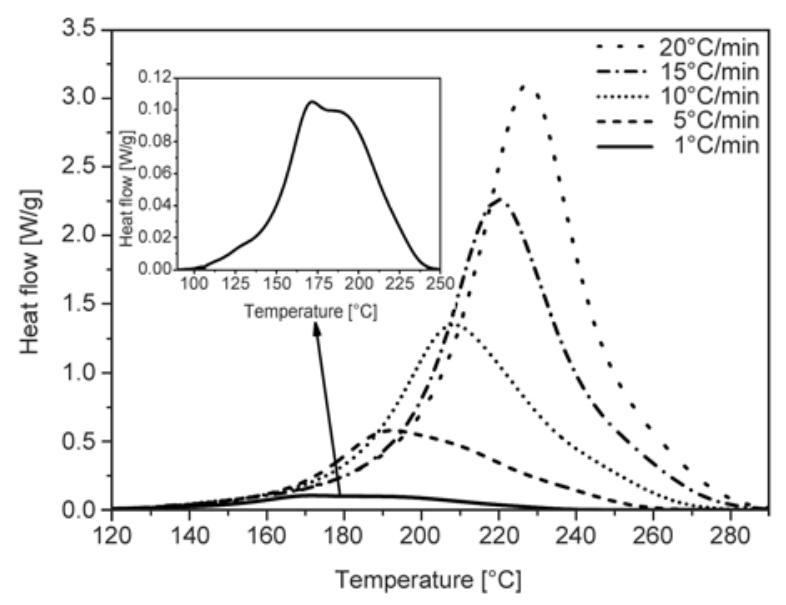

Figure 4. DSC thermograms of benzoxazine with $16.7 \mathrm{~mol} \%$ of thiodiphenol at different heating rates

structure. DSC thermograms of mixtures containing $16.7 \mathrm{~mol} \%$ of thiodiphenol obtained at different heating rates are shown in Figure 4. The exothermal signal of curing comprised of several overlapped peaks (Figure 4). The overlapping was more evident when lower heating rates were applied. This clearly indicated that the reaction of benzoxazine with thiodiphenol had at least two curing stages, which is in accordance with the known mechanisms of benzoxazine curing with phenolic accelerators $[12,13,33$, 34]. The lower the heating rate, the more noticeable the boundary between the reactions stages. Nevertheless, the heating rate showed no effect on the total exothermic reaction heat estimated from the area under the overlapped peaks. The average total exothermic reaction heat was $370 \mathrm{~J} / \mathrm{g}$.

To investigate the curing stages further on, the effect of thiodiphenol amount on the curing was studied. Additional DSC experiments at fixed heating rate of $1^{\circ} \mathrm{C} / \mathrm{min}$ were performed. At such a slow heating rate the effect of the accelerator on the progress of the curing was clearly observable. As it can be seen in Figure 5 the amount of thiodiphenol had the greatest impact on the initial stage of the reaction, which was the oxazine ring opening (formation of compound II in Figure 1a). The next process, related to the polymerization and cross-linking (formation of final cured compound III in Figure 1a), was not affected to the same degree.

DSC peaks fitting and deconvolution (Figure 5) was performed by the OriginPro program using the Pearson VII distribution, which gave best DSC peaks fitting and deconvolution results. In the case of benzoxazine without accelerator (Figure 5a) the two deconvoluted peaks may be associated with the thermally accelerated ring-opening accompanied by autocatalytic reaction ( $\Delta$ in Figure 5 ) and the diffusion-controlled step in curing reaction ( $\square$ in Figure 5), respectively. The reaction of thermally accelerated ringopening is shown in Figure 1a and results in formation of compound II. The autocatalytic reaction, which mechanism is the same as depicted in Figure $1 \mathrm{c}$, involves the catalysis of ring-opening reaction by hydrogen bond formation between hydroxyl group of the compound II and other benzoxazine molecule. The diffusion-controlled step comprises same reactions but the mobility of molecules is hindered. Most likely, the sterical hindrance prevents the autocatalytic ring-opening reaction through hydrogen bond formation at this stage.

On the other hand, for mixtures with thiodiphenol, another peak ( $\circ$ in Figure 5) emerged during the fitting process. Since the new peak emerged at the beginning of the curing process it was assigned to the accelerated oxazine ring opening (mechanisms presented in Figures $1 b$ and 1c). With increasing the amount of the accelerator the peak shifted to lower temperatures and became even more noticeable. Note, the deconvoluted peak (marked as $\Delta$ ), assigned to the autocatalytic reaction, associated to the benzoxazine hydroxyl groups, is still present in Figures $5 \mathrm{~b}, 5 \mathrm{c}$, and $5 \mathrm{~d}$. In the case of the highest amount of the accelerator (Figure 5d) the peak of the diffusion-controlled step disappeared, which may be explained by involvement of smaller accelerators molecules in the curing reactions. Based on this observation it may be deducted that the formation of compounds $\mathrm{V}$ (Figure 1c) is more favorable than the formation of compounds II and/or III. Furthermore, it is possible to conclude that the reaction of benzoxazine with thiodiphenol leads to products of lower cross-linking density.

\section{Conclusions}

The influence of phenolic, mercapto, amino and imidazole accelerators on the benzoxazine curing process was studied and discussed in detail. The model-free kinetics analysis of DSC data showed that thiodiphenol is the best choice among the tested accelerators. In order to investigate the curing of benzoxazine/thiodiphenol mixture in detail the accelerator amount was varied. By low heating rate DSC analysis exothermic signals of curing, composed of several overlapped peaks, were obtained. The peaks were sensibly associated to catalytic ring-opening, 

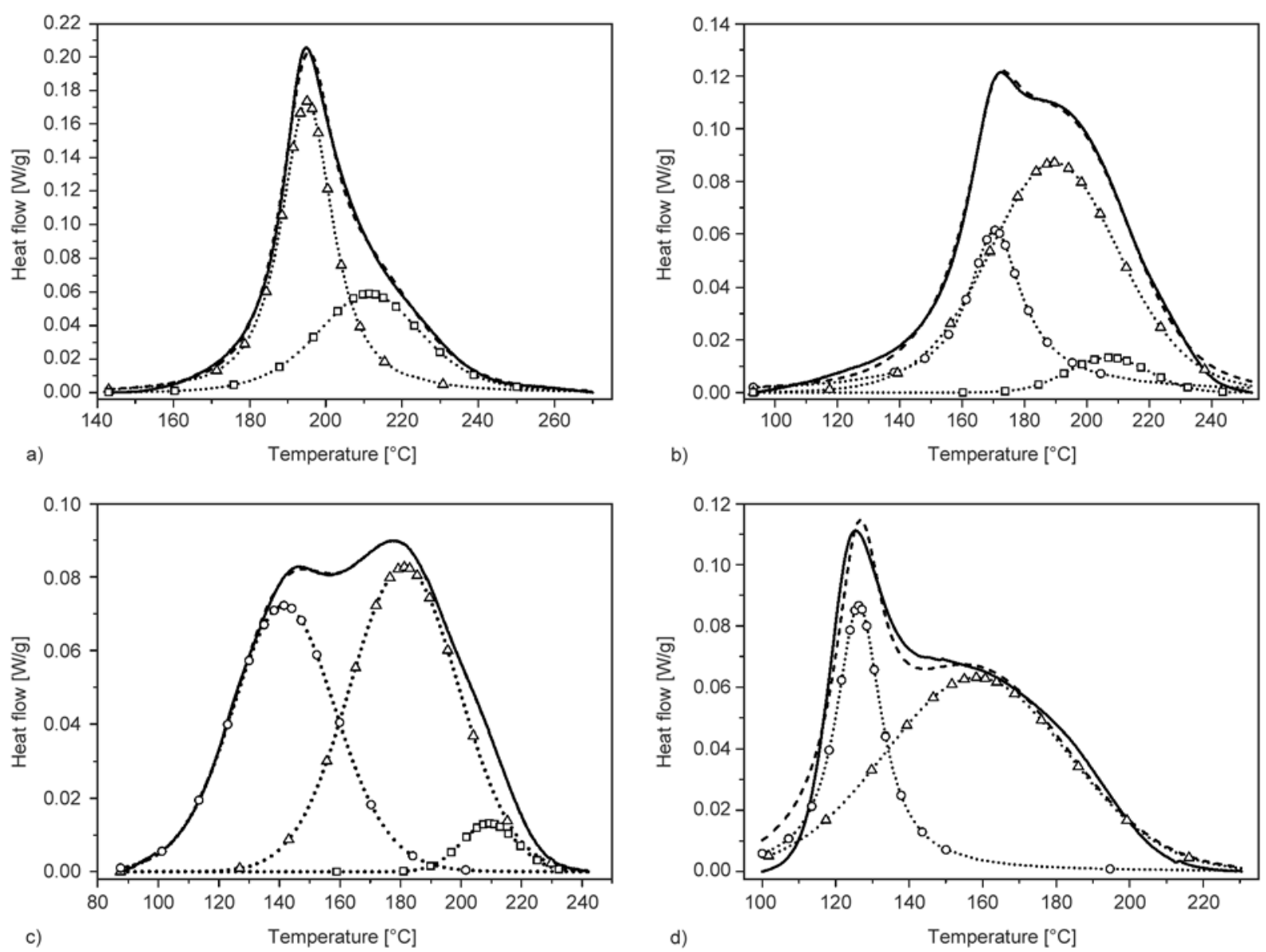

Figure 5. DSC curing peaks (solid line) and peaks obtained by deconvolution (dashed lines) for benzoxazine (BOX) with different amount of thiodiphenol ((a) 0, (b) 5, (c) 20, (d) $50 \mathrm{wt} \%$. Peak assignment: thermally accelerated ringopening and autocatalytic reaction $(\Delta)$, diffusion-controlled step $(\square)$, catalytic ring-opening $(\circ)$.

thermally accelerated ring-opening and to the diffusion-controlled step. The amount of added accelerator affected particularly the ring-opening and diffusion-controlled steps. The kinetic regime in the diffusion-controlled step was dominated by cross-linking density of benzoxazine resin, which is also dependent on the accelerator amount and functionality.

\section{Acknowledgements}

The financial support of this work by the Slovenian Ministry of Higher Education, Science and Technology (Grant P2-0191) is gratefully acknowledged.

\section{References}

[1] Ishida H., Rodriguez Y.: Catalyzing the curing reaction of a new benzoxazine-based phenolic resin. Journal of Applied Polymer Science, 58, 1751-1760 (1995). DOI: 10.1002/app.1995.070581013
[2] Ning X., Ishida H.: Phenolic materials via ring-opening polymerization of benzoxazines: Effect of molecular structure on mechanical and dynamic mechanical properties. Journal of Polymer Science Part B: Polymer Physics, 32, 921-927 (1994).

DOI: $10.1002 /$ polb.1994.090320515

[3] Ishida H., Allen D. J.: Mechanical characterization of copolymers based on benzoxazine and epoxy. Polymer, 37, 4487-4495 (1996).

DOI: 10.1016/0032-3861(96)00303-5

[4] Ishida H., Allen D. J.: Physical and mechanical characterization of near-zero shrinkage polybenzoxazines. Journal of Polymer Science Part B: Polymer Physics, 34, 1019-1030 (1996).

DOI: 10.1002/(sici)1099-0488(19960430)34:6<1019:: aid-polb1>3.0.co;2-t

[5] Ishida H., Low H. Y.: A study on the volumetric expansion of benzoxazine-based phenolic resin. Macromolecules, 30, 1099-1106 (1997).

DOI: $10.1021 / \mathrm{ma960539a}$

[6] Grishchuk S., Mbhele Z., Schmitt S., Karger-Kocsis J.: Structure, thermal and fracture mechanical properties of benzoxazine-modified amine-cured DGEBA epoxy resins. Express Polymer Letters, 5, 273-282 (2011). DOI: 10.3144 /expresspolymlett.2011.27 
[7] Grishchuk S., Schmitt S., Vorster O. C., Karger-Kocsis J.: Structure and properties of amine-hardened epoxy/ benzoxazine hybrids: Effect of epoxy resin functionality. Journal of Applied Polymer Science, 124, 2824 2837 (2012).

DOI: $10.1002 /$ app.35302

[8] Grishchuk S., Sorochynska L., Vorster O. C., KargerKocsis J.: Structure, thermal, and mechanical properties of DDM-hardened epoxy/benzoxazine hybrids: Effects of epoxy resin functionality and ETBN toughening. Journal of Applied Polymer Science, 127, 5082-5093 (2013).

DOI: $10.1002 /$ app.38123

[9] Jin L., Agag T., Ishida H.: Bis(benzoxazine-maleimide)s as a novel class of high performance resin: Synthesis and properties. European Polymer Journal, 46, 354-363 (2010).

DOI: 10.1016/j.eurpolymj.2009.09.013

[10] Wang J., Fang X., Wu M-Q., He X-Y., Liu W-B., Shen $\mathrm{X}$-D.: Synthesis, curing kinetics and thermal properties of bisphenol-AP-based benzoxazine. European Polymer Journal, 47, 2158-2168 (2011).

DOI: $10.1016 /$ j.eurpolymj.2011.08.005

[11] Low H. Y., Ishida H.: An investigation of the thermal and thermo-oxidative degradation of polybenzoxazines with a reactive functional group. Journal of Polymer Science Part B: Polymer Physics, 37, 647-659 (1999). DOI: $10.1002 /($ sici)1099-0488(19990401)37:7<647:: aid-polb16>3.0.co;2-1

[12] Wang Y-X., Ishida H.: Cationic ring-opening polymerization of benzoxazines. Polymer, 40, 4563-4570 (1999). DOI: 10.1016/S0032-3861(99)00074-9

[13] Dunkers J., Ishida H.: Reaction of benzoxazine-based phenolic resins with strong and weak carboxylic acids and phenols as catalysts. Journal of Polymer Science Part A: Polymer Chemistry, 37, 1913-1921 (1999). DOI: $10.1002 /($ sici) 1099-0518(19990701)37:13<1913 :aid-pola4>3.0.co;2-e

[14] Sudo A., Kudoh R., Nakayama H., Arima K., Endo T.: Selective formation of poly $(\mathrm{N}, \mathrm{O}$-acetal) by polymerization of 1,3-benzoxazine and its main chain rearrangement. Macromolecules, 41, 9030-9034 (2008).

DOI: $10.1021 / \mathrm{ma} 8013178$

[15] Andreu R., Reina J. A., Ronda J. C.: Carboxylic acidcontaining benzoxazines as efficient catalysts in the thermal polymerization of benzoxazines. Journal of Polymer Science Part A: Polymer Chemistry, 46, 6091-6101 (2008).

DOI: $10.1002 /$ pola.22921

[16] Andreu R., Espinosa M. A., Galià M., Cádiz V., Ronda J. C., Reina J. A.: Synthesis of novel benzoxazines containing glycidyl groups: A study of the crosslinking behavior. Journal of Polymer Science Part A: Polymer Chemistry, 44, 1529-1540 (2006).

DOI: $10.1002 /$ pola.21255
[17] Kim H-D., Ishida H.: Study on the chemical stability of benzoxazine-based phenolic resins in carboxylic acids. Journal of Applied Polymer Science, 79, 1207-1219 (2001).

DOI: $10.1002 / 1097-4628(20010214) 79: 7<1207:$ :aidapp80>3.0.co;2-3

[18] Chow W. S., Grishchuk S., Burkhart T., Karger-Kocsis J.: Gelling and curing behaviors of benzoxazine/epoxy formulations containing 4,4'-thiodiphenol accelerator. Thermochimica Acta, 543, 172-177 (2012). DOI: $10.1016 /$ j.tca.2012.05.015

[19] Jang J., Shin S.: Cure studies of a benzoxazine-based phenolic resin by isothermal experiment. Polymer Journal, 27, 601-606 (1995).

DOI: $10.1295 /$ polymj.27.601

[20] Shi Z., Yu D., Wang Y., Xu R.: Nonisothermal cure kinetics in the synthesis of polybenzoxazine-clay nanocomposites. Journal of Applied Polymer Science, 88, 194-200 (2003).

DOI: $10.1002 / a p p .11640$

[21] Su Y-C., Yei D-R., Chang F-C.: The kinetics of B-a and $\mathrm{P}-\mathrm{a}$ type copolybenzoxazine via the ring opening process. Journal of Applied Polymer Science, 95, 730737 (2005).

DOI: 10.1002/app.21244

[22] Yei D-R., Fu H-K., Chen W-Y., Chang F-C.: Synthesis of a novel benzoxazine monomer-intercalated montmorillonite and the curing kinetics of polybenzoxazine/clay hybrid nanocomposites. Journal of Polymer Science Part B: Polymer Physics, 44, 347-358 (2006). DOI: $10.1002 /$ polb.20693

[23] Santhosh Kumar K. S., Reghunadhan Nair C. P., Ninan K. N.: Rheokinetic investigations on the thermal polymerization of benzoxazine monomer. Thermochimica Acta, 441, 150-155 (2006).

DOI: $10.1016 /$ j.tca.2005.12.007

[24] Jubsilp C., Punson K., Takeichi T., Rimdusit S.: Curing kinetics of benzoxazine-epoxy copolymer investigated by non-isothermal differential scanning calorimetry. Polymer Degradation and Stability, 95, 918-924 (2010).

DOI: $10.1016 /$ j.polymdegradstab.2010.03.029

[25] Jubsilp C., Damrongsakkul S., Takeichi T., Rimdusit S.: Curing kinetics of arylamine-based polyfunctional benzoxazine resins by dynamic differential scanning calorimetry. Thermochimica Acta, 447, 131-140 (2006). DOI: $10.1016 /$ j.tca.2006.05.008

[26] Chutayothin P., Ishida H.: Cationic ring-opening polymerization of 1,3-benzoxazines: Mechanistic study using model compounds. Macromolecules, 43, 45624572 (2010).

DOI: $10.1021 / \mathrm{ma901743h}$

[27] Santhosh Kumar K. S., Reghunadhan Nair C. P., Ninan $\mathrm{K}$. N.: Investigations on the cure chemistry and polymer properties of benzoxazine-cyanate ester blends. European Polymer Journal, 45, 494-502 (2009). DOI: $10.1016 /$ j.eurpolymj.2008.11.001 
[28] Santhosh Kumar K. S., Reghunadhan Nair C. P., Sadhana R., Ninan K. N.: Benzoxazine-bismaleimide blends: Curing and thermal properties. European Polymer Journal, 43, 5084-5096 (2007).

DOI: $10.1016 /$ j.eurpolymj.2007.09.012

[29] Jayamohan Das D. L., Rayeev R., Rajeev R. S., Santhosh Kumar K. S.: Synthesis, characterization, curing and thermal decomposition kinetics of bisphenol-A based polybenzoxazine. International Journal of Scientific and Technology Research, 2, 146-155 (2013).

[30] Vyazovkin S., Dollimore D.: Linear and nonlinear procedures in isoconversional computations of the activation energy of nonisothermal reactions in solids. Journal of Chemical Information and Computer Sciences, 36, 42-45 (1996). DOI: $10.1021 / \mathrm{ci} 950062 \mathrm{~m}$

[31] Vyazovkin S.: Evaluation of activation energy of thermally stimulated solid-state reactions under arbitrary variation of temperature. Journal of Computational Chemistry, 18, 393-402 (1997).

DOI: $10.1002 /(\mathrm{SICI}) 1096-987 \mathrm{X}(199702) 18: 3<393:$ :

\section{AID-JCC9>3.0.CO;2-P}

[32] Vyazovkin S.: Modification of the integral isoconversional method to account for variation in the activation energy. Journal of Computational Chemistry, 22, 178183 (2001).

DOI: 10.1002/1096-987X(20010130)22:2<178::AIDJCC $5>3.0 . \mathrm{CO} ; 2-\#$

[33] Riess G., Schwob J. M., Guth G., Roche M., Laude B.: Ring opening polymerization of benzoxazines - A new route to phenolic resins. in 'Advances in polymer synthesis' (eds.: Culbertson B., McGrath J.) Springer, New York, Vol 31, 27-49 (1985).

DOI: $10.1007 / 978-1-4613-2121-72$

[34] Wang Y-X., Ishida H.: Synthesis and properties of new thermoplastic polymers from substituted 3,4-dihydro2H-1,3-benzoxazines. Macromolecules, 33, 2839-2847 (2000). DOI: $10.1021 / \mathrm{ma9909096}$
[35] Liu C., Shen D., Sebastián R. M., Marquet J., Schönfeld R.: Catalyst effects on the ring-opening polymerization of 1,3-benzoxazine and on the polymer structure. Polymer, 54, 2873-2878 (2013). DOI: $10.1016 /$ j.polymer.2013.03.063

[36] Vyazovkin S., Sbirrazzuoli N.: Isoconversional kinetic analysis of thermally stimulated processes in polymers. Macromolecular Rapid Communications, 27, 15151532 (2006).

DOI: $10.1002 /$ marc. 200600404

[37] Musa A., Kiskan B., Yagci Y.: Thiol-benzoxazine chemistry as a novel Thiol-X reaction for the synthesis of block copolymers. Polymer, 55, 5550-5556 (2014). DOI: $10.1016 /$ j.polymer.2014.06.076

[38] Málek J.: The kinetic analysis of non-isothermal data. Thermochimica Acta, 200, 257-269 (1992). DOI: 10.1016/0040-6031(92)85118-F

[39] Vyazovkin S., Burnham A. K., Criado J. M., PérezMaqueda L. A., Popescu C., Sbirrazzuoli N.: ICTAC Kinetics Committee recommendations for performing kinetic computations on thermal analysis data. Thermochimica Acta, 520, 1-19 (2011). DOI: $10.1016 /$ j.tca.2011.03.034

[40] Kissinger H. E.: Reaction kinetics in differential thermal analysis. Analytical Chemistry, 29, 1702-1706 (1957). DOI: 10.1021/ac60131a045

[41] Friedman H. L.: Kinetics of thermal degradation of char-forming plastics from thermogravimetry. Application to a phenolic plastic. Journal of Polymer Science Part C: Polymer Symposia, 6, 183-195 (1964). DOI: $10.1002 /$ polc. 5070060121

[42] Ozawa T.: A new method of analyzing thermogravimetric data. Bulletin of the Chemical Society of Japan, 38, 1881-1886 (1965). DOI: $10.1246 /$ bcsj.38.1881

[43] Sbirrazzuoli N., Girault Y., Elégant L.: Simulations for evaluation of kinetic methods in differential scanning calorimetry. Part 3 - Peak maximum evolution methods and isoconversional methods. Thermochimica Acta, 293, 25-37 (1997). DOI: $10.1016 / \mathrm{S} 0040-6031(97) 00023-3$ 